\title{
An Instantaneous Corrosion Monitoring Technique based on Combining Modified Electrochemical Noise and Artificial Neural Network for Determination of Corrosion Type and 2014 Aluminium Alloy Corrosion Rate in $\mathrm{NaCl}$ and $\mathrm{Ce}\left(\mathrm{NO}_{3}\right)_{3}$ solutions
}

\author{
Qiangfei Hu${ }^{1}$, Tao Zhang ${ }^{2, *}$, Shaohua Chen ${ }^{1}$, Kun Hu${ }^{1}$, Qing Yin ${ }^{3}$, Fuhui Wang ${ }^{2}$ \\ ${ }^{1}$ Anhui Province Engineering Laboratory of Advanced Building Materials, Anhui Jianzhu University, \\ Hefei 230601, P. R. China \\ ${ }^{2}$ Corrosion and Protection Division, Shenyang National Laboratory for Materials Science, \\ Northeastern University, Shenyang 110819, P. R. China \\ ${ }^{3}$ Harbin Engineering University, Harbin 150001, P. R. China \\ *E-mail: zhangtao@mail.neu.edu.cn
}

Received: 1 November 2021 / Accepted: 7 December 2021 / Published: 5 January 2022

\begin{abstract}
Electrochemical emission spectroscopy (EES), an improved electrochemical noise measurement, was applied for monitoring corrosion rate of 2014 aluminium alloy in $\mathrm{NaCl}$ and $\mathrm{Ce}\left(\mathrm{NO}_{3}\right)_{3}$, and corrosion type was analysed by wavelet transform and artificial neural network. Reliability of EES was verified by monitoring corrosion of 2014 aluminium alloy in the passivation, pitting and inhibition systems, because the results from EES, linear polarization resistance technique and morphology observation were in good agreement. In order to process data obtained by EES, artificial neural network was introduced to build the relationship between wavelet results and corrosion types, and results of confusion matrix and receiver operating characteristic curve demonstrated that artificial neural network is an excellent method for intelligent recognition for corrosion type.
\end{abstract}

Keywords: electrochemical noise; corrosion monitoring; corrosion rate; corrosion type; artificial neural network

\section{$\underline{\text { FULL TEXT }}$}

(C) 2022 The Authors. Published by ESG (www.electrochemsci.org). This article is an open access article distributed under the terms and conditions of the Creative Commons Attribution license (http://creativecommons.org/licenses/by/4.0/). 